\title{
Information management platform of large-scale custom-built ambry material technology archives
}

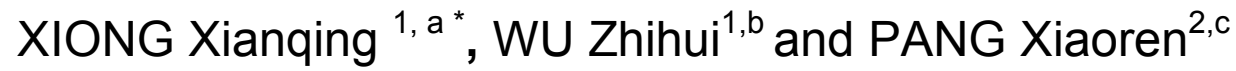 \\ ${ }^{1}$ College of Furniture and Industrial Design, Nanjing Forestry University, Nanjing 210037, China \\ ${ }^{2}$ Zhejiang Shenghua Yunfeng Greeneo Co., Ltd. 313220,Zhejiang, China \\ a96xiong0450@sina.com, bwzh550@sina.com, c440790220@qq.com
}

\begin{abstract}
Keywords: large-scale custom-built ambry; material archives; information management; platform. Abstract. This paper defined the material archives information management by analyzing the bill of the large-scale custom-built ambry material. This paper built the information management platform of large-scale custom-built ambry material technology archives preliminarily, including product mix, material sorting, brand and material maintenance. The author also illustrated the specific content of information of archives management. The paper would provide reference for ERP.
\end{abstract}

\section{Introduction}

Nowadays manufacturing process has become digital and informational. A lot of furniture enterprises choose the Enterprise Resource Planning (ERP) to achieve the integration of logistics, fund, manage. The basic information management is Material information management. Material management includes analyzing the stock, purchasing, stock management of finished and semi-finished products and some other managemen[1]. The information management is the key to cut the cost and information manage efficiently.

Building the information management platform of mass customization ambry material technology archives could provide convenience for stock management and resource sharing. The paper built the easy operation information management platform based on the ERP system.

\section{Foundation of material information management platform}

\section{Bill and code of materiel}

Furniture materiel includes all products, semi-manufactures, material, fitting component, consumables etc[2]. Bill of Materials (BOM) is a typical tree structure. Every provide has the only BOM, which decides the component quantity and relationship. The whole BOM table is very complex. However, only a few components are as the key to furniture product quality, which are always called the key parts or important parts.

Sort -code of material is the base of the material information management by using number and letter to express property, function, structure and so on. The code is a technical means for exchanging material information and is the important base for kinds of information system. Managing the sort-code of material is a huge engineering. Product is the core of all problems for manufacturing. Bill of material is the base of the production flow. So understanding and building the material bill is the first step of applying ERP system. The leading work should be done normally including classifying, coding, main file before writing the material bill[3]. The sort-code of components is divided into standard components and unstandard components in mass customization ambry products. Then the code system would be clear and direct.

\section{Meaning of the material information management}

Material information management is helpful for furniture products to improve quantity. In addition, it can provide the convenience for stock management and resource sharing based on ERP. 
In mass customization cabinets enterprises, the material information management includes inventory management, production material mistakes of management, bill of the whole material. In the management progress, the system should have overall consideration, classify the whole material according to the product structure. Write the bill according to the classification list then update the information when changing.

\section{The information management platform}

According to the practice of ERP and the meaning of material structure management, the information management platform system consists the managements of product structure, material sorting, brand, material maintenance, as shown in Fig 1[3].

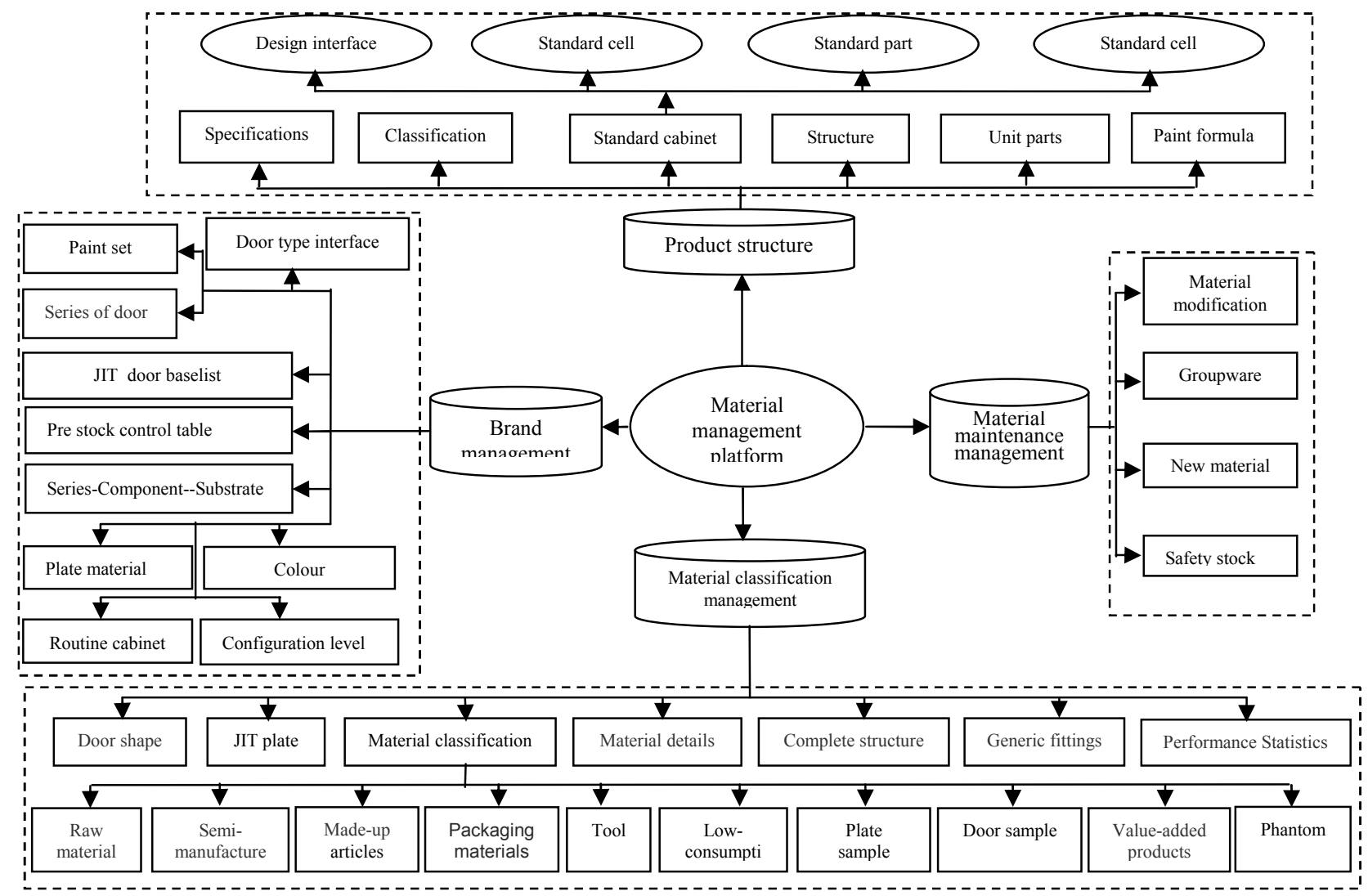

Fig.1 Information management platform of large-scale custom-built ambry material technology archives

\section{Management of product structure}

Mass customization of cabinet products is made up with some components. The complication-degree of product decides the type of product structure. In fact, the management is managing the product components.

\section{Characteristic}

Nowadays, the cabinet is made up with the body, door plank, drawer, table etc. The cabinet body includes wall cupboard and floor cabinet, which can be divided into standard body, unstandard body, special body and some other fittings. The structure of the cabinet body is assembled by standard components, unstandard components and some other fittings. The components are connected by standard adapting pieces. There are many kinds of door planks including paint door, molded door, wood door. Different structures decide different numbers of components and types of connecting. The darwer planks are also connected by standard connector. The table plat's structure has the relationship with materials and modle, and the table is made up with the plat and corner. The individuation is mainly reflected in the material, colour and model. 


\section{Product components}

Product components are the basic parts of furniture, which are the smallest elements when processed. In mass customization of cabinet products, the components can be divided into standard parts and unstandard parts. The unstandard parts are always the custom components according to the scene situation in customer kitchen. In a word, the standard parts are the core of mass customization. The fewer the unstandard parts are, the faster the production would be, the less the lead time would be. It's the key of mass customization.

According of the form regularity, same process and iterancy, the furniture component will be divided into plate, frame, drawer, pillar, strip and so on[4]. For custom cabinets, plate is the main of it. There are side plate, shelf, backboard, baseboard, door plank etc. The drawer's parts have side plate, tap plate, draw back plate, baseboard etc. The pillar is used to decorate and the strip is assistant such as moulding, crossrail,triangular wood etc. In addition, cabinet also has special-shapedparts.

\section{Information management of product structure}

According to the analyses of product structure, there are a great variety of parts to compose cupboards and in different constructions. To manage the parts in different constructions intergrated and informatization, starting with specifications of a unit of a product set is needed, and put units in different sorts in terms of the method of classification management, so as to draw up the structure of standard unit, and analyse it to get the key points of its informatization management, such as joints design classification management, standard units management, standard component and assembly unit management. Next, determin the feature of components and assembly units and number them, including both standard and non-standard cupboard units. Besides, considering the structure of door sheets, the classification management of painting process is to be mentioned as well. As a result, the product structure information management of large scaled customed cupboard contains the parts above, as shown in Fig.1.

\section{Brands (series)Management}

\section{Classification of brands (series) management}

For enterprises, the type of product, style is often diverse, how to assemble different types of products in different features and style with limited parts is the key to enterprise information management, and to build brand (series) basic information management platform as well. For furniture enterprises which provide large scale customization, component and assembly units mainly consists of standard parts and non-standard parts. To product a variety of productions, mostly differs from material of components, the structural type of doors, colour matching, the structure of cupboards and table facet.

Material of component and assembly units should be classified and determined according to all the material of standard components and assembly units which compose all kinds of products. Ordinarilly base material and upholstery, such as wood panel, MDF with fireproof veneer, veneer decorative panels and decorative panels affixed impregnated paper, mostly panels. The types of structures of door panels are the key to custom-made cunboards on large scale, for instance, integral panel series, fireproof panel series, painted panel series, blistered series, wood panel series, aluminum series, custom-made series and crystal series, they are tatalli different from inside structure and apperence. Cupboard in brand need to determin components and assembly units on the basis of different brands. The material and colour of table facet is crucially important to cupboards. Material contains wood, stone and variety of colour in demand.

\section{Content of information management platform of brands (series) management}

From the analyses above, basis material information, door panel information, product colour information and matching each other information should be included in the content of informatization management platform aim to custom-made cunboards on large scale. Details are mentioned in Fig.1, 
including serie-assembly unit-basis material, JIT door-type sheet, preliminary inventory table, series of door panel and laquer settings, joints of doors, material of table facet, colour classification settings, cupboard settings and configuration. Specifically table facet series, material of table facet, laquer settings, colour classification, door panel series, cupboard in brands, configuration and serie-assembly unit-basis material, and classification manage technique parameters and requirement details.

\section{Material classification management}

\section{Basis of material classification}

In the process of custom-made cunboards on large scale, good material management is closely related to distinct material classification. The work of material classification of custom-made cunboards on large scale, general basis is classifying in information (according to the property and characteristic of materials, distinguish and classify materials in specific principle and method, and create classification system and arrangement order to manage and utilize information conveniently)[5]. Classifying components and assembly units on the basis of the principle of group technology. Classifying components is to put different components into groups, which is done on top of analyzing the similarity of components. Classify components according to geometrical characteristics, craft feature, production and management feature, and then get into the process of designing craft and production[6]. This method classifies a variety of components into groups in specific standard, and beyond that accomplish the process of production, thus makes designing, craft and producting management more reasonable, improved the quality and quantity of products. From a workshop's view, batch is increased, but number of variety of products is reduced, which is easier to carry out producting methods which has higher efficiency, thus labor productivity will be improved.

\section{To build an information management platform of material classification}

An information management platform of material classification could be divided into 7 parts in terms of characteristics of cupboard products and material classification rules, they are shape of door panels, customed JIT table facet, material classification, group structure, general units and performance statistics management, including joints designing, pre-stock and material cost situation as well, as shown in Fig.1. Door panels are determined by cupboards, such as glass doors, craft doors, arc-shaped doors, plank doors, wood doors and grid doors. Auxiliary components which help to build cupboards are included as well, such as ceiling, mound layer, glass, waist line and bars. Customed JIT table facet is determined by the area of products, so does its informatization management. Informatization management of material details includes self-made semi-finished product management and bought material management according to the feature of cupboard products,including materials (panels, alumimun, table facet, metal sectors, consumable items, chemical items, sinks, decorative items, electrical items, and tube), semi-finished products, products (integral panel series, fireproof panel series, laqure series, plastic series, wood series and aluminum series), packaging items (outside package, inside package and other package), tools (equipment accessories, installing tools, fixing tools, other tools), low value items (processing consumable items, office items and labor protecting items), samples of table panels (different brands), value added products (pots, cooking tools). Material detail management is to manage basic features of materials informatizationally, including name, norm, purchased inventory, consuming, instant changes, which is the core of material informatization management. Group structure aims to that all units combines the cupboard-material added up management of one set of product. General units are metal units forms product, including managing three-in-one joint, dowel, dust-proof mat, shelf support, buckle, cabine, cupboard joint, glazing bead. Performance statistics management is to count self-made items, accessories, electric items, table facet and decorative items. 


\section{Material maintaining management}

Maintaining management is unified manage changes in the process of informatization management of custom-made cunboards on large scale, such as structural change, routine change and newly-added materials. Specifically including material alter condition, assembly units apply condition, newl-added material utilize apply condition and safety stock management condition. Material alter condition should include the process and detail check-up. Assembly unit apply is a manage process in terms of necessary supply, including application and approval process. Newly-addad material apply includes adding units in batches, appkication, review and approval of newly added material, and classification of newly-added material. Safety stock management includes adjusting detail management, daily maintaining management, purchasing bill management and purchasing process management. Material preserve management alters constantly.Informatization management platform can help to reduce mistakes.

\section{Conclusion}

Material management is the bridge connecting manufacture, purchase and market. Material management plays an important role in manufacturer and delivery which offers the stock situation. Directly affect the production orders whether or not they are completed according to plan. Building the information management platform of material archives makes a contribution to collection, delivery,save and maintenance of enterprise material information and help manager make decisions. The platform could solve the problems of mass complicated material information and provide convenience for the harmonization between the departments of an enterprise and resource sharing. The platform is one of the competitive powers of enterprise information management.

\section{Acknowledgements}

1)A Project Funded by the Priority Academic Program Development of Jiangsu Higher Education Institutions(PAPD).

2)Research institute of wood industry,Chinese academy of Forestry, Technology Innovation Alliance of wood/bamboo industry (TIAWBI2014-05).

3)National 863 planning project “Modularized customization agile manufacturing technology for wood and bamboo products” (2010AA101705).

\section{Reference:}

[1] Xiong X Q, Wu Z H. Application of information collection and processing technology in material management of mass custom-made furniture [J]. Journal of Central South University of Forestry \&Technology, 2012 (11): 200-205.

[2] Hu M. Research on BOM Processing in Integration of Enterprise [J].Computer Engineering, 2001, 27(6): 22-24.

[3] Wang B Y. Classification and Coding of Information. Beijing: National Defence Industry Press, 2003.

[4] Li J. The study of furniture flexible production [D]. Nanjing Forestry University, 2004.

[5] Xiong X Q. Application of information collection and processing technology of mass custom-made furniture [D]. Nanjing Forestry University, 2012.

[6] China National Technical Committee of Standardizationfor Documentation. Science and technology information system standards and guidelines : the 3rd Information classification and coding standard. Beijing: Chinese Standards Press, 1996. 